\title{
DPPH scavenging activity of some Bis-benzimidazole derivatives
}

\author{
Amine Ouaket *, Fatiha Moughaoui, Asmae Laaraibi, Souad Hamdouch, Mohammed Berrada, and \\ Noureddine Knouzi
}

Biomolecules and Organic Synthesis Laboratory, University Hassan II of Casablanca, Faculty of Sciences Ben M'sick, Department of Chemistry, Av Driss El Harti, Sidi Othman, Casablanca, P.B. 7955, Morocco

\begin{abstract}
As part of our research on substituted benzimidazoles, we are interested in the synthesis of new heterocyclic molecules. This new organic molecule is a subclass of quinolines with a wide variety of biological properties. In order to affect the binding of quinoline to our bis-benzimidazole derivatives, we have chosen the "azo" bond as a means of attachment. To achieve our goal, we investigated different parameters for the reactions to determine the conditions to obtain the best results. This article discusses the antioxidant activity of our molecules using the DPPH method.
\end{abstract}

Keywords: Synthesis; benzimidazole; Bis-benzimidazole; antioxidant activity; DPPH.

\section{Introduction}

Heterocyclic molecules belong to a class of cyclic compounds harboring one or more heteroatoms, containing heteroatoms of the same element or even different ones different ${ }^{1,2}$. The role of heterocyclic compounds has become more and more important in recent years particularly in the design of new classes of compounds with demonstrated activities (corrosion inhibitors, dyes, and stabilizers...), as well in the medicinal field (vitamins, hormones, antibiotics, and antineoplastics ...) ${ }^{3,4}$. Among these heterocyclic compounds are the benzimidazoles, the series of benzimidazole which is one of the most versatile in therapeutic chemistry.

Benzimidazole is an important pharmacophore and a privileged structure in medicinal chemistry. This bicyclic compound consists of an imidazole ring, containing two nitrogen atom at adjacent position fused to a benzene ring ${ }^{5-7}$.<smiles>c1ccc2[nH]cnc2c1</smiles>

Figure 1. Benzimidazole

The first benzimidazole was synthesized by Hoebrecker in 1872, who obtained 2,5(or 2,6)dimethylbenzimidazole by using 2-nitro-4methylacetanilide ${ }^{8,9}$.

*Corresponding author: Amine Ouaket

Email address: amine.ouaket@ gmail.com DOI: http://dx.doi.org/10.13171/mjc8219041101ao
Benzimidazole (Fig. 1) and bis-benzimidazole (Fig. 2) derivatives are bioactive compounds.

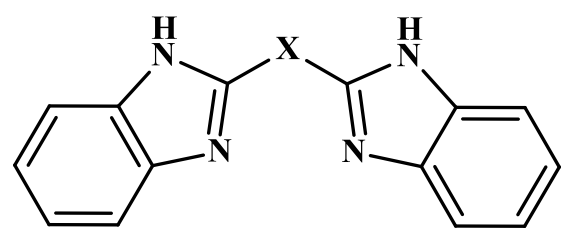

Figure 2. Bis(1H-benzimidazole)

These heterocycles can be prepared by different synthetic methods ${ }^{10-15}$. Recent studies have shown that these heterocycles have several biological applications in chemistry ${ }^{16}$ and in biology ${ }^{17,18}$.

This work discusses the antioxidant activity of our compounds. Antioxidants are chemical compounds capable of effectively minimizing retentions, a retardant of lipid peroxidation, with no effect on the sensorial and nutritional properties of the food product ${ }^{19}$. They help to retain the quality and increase the shelf life of the product.

Several in vitro and in vivo methods are used to evaluate, in vitro and in vivo, the antioxidant activity by trapping different radicals, such as peroxides (ROO•) by the methods ORAC (Oxygen Radical Absorbance Capacity) and TRAP (Total Radical Trapping Antioxidant Parameter); Ferric ions by the FRAP method (Ferricion Reducing Antioxidant Parameter) or the ABTS - (ammonium salt of 2,2'azinobis-3-ethylbenzothiazoline-6-sulfonic acid), as well as the method using the free radical DPPH • (diphenyl-picrylhydrazyl). 
This work discusses the antioxidant activity of a set of Bis-benzimidazoles developed in our research group using the DPPH method.

\section{Experimental}

\section{General procedure for the synthesis}

In the first Time, the unsubstituted bis(benzimidazole) derivatives are synthesized (Fig. 3) with a condensation reaction of 1,2-phenylenediamine a with diacids: Sebacic acid and Terephthalic acid.

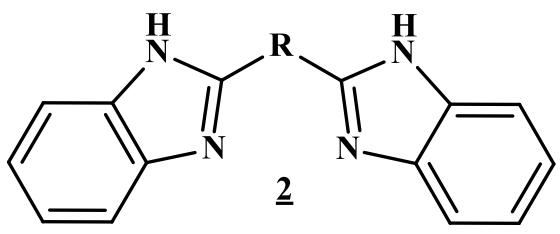

$$
\begin{aligned}
& \underline{\mathbf{2} \mathbf{a}}: \mathrm{R}=-(\mathrm{CH})- \\
& \underline{\mathbf{2 b}}: \mathrm{R}=\underset{64}{-\mathrm{CH}}-
\end{aligned}
$$

Figure 3. Bis(1H-benzimidazole)

The nitration of our molecules is carried out according to the procedure described in the experimental part ${ }^{1}$. By nitrating the unsubstituted Bisbenzimidazoles such that this nitration reaction is carried out at $0-5{ }^{\circ} \mathrm{C}$ with $\mathrm{HNO}_{3}(65 \%)$ in solution with $\mathrm{H}_{2} \mathrm{SO}_{4}(92 \%)$.

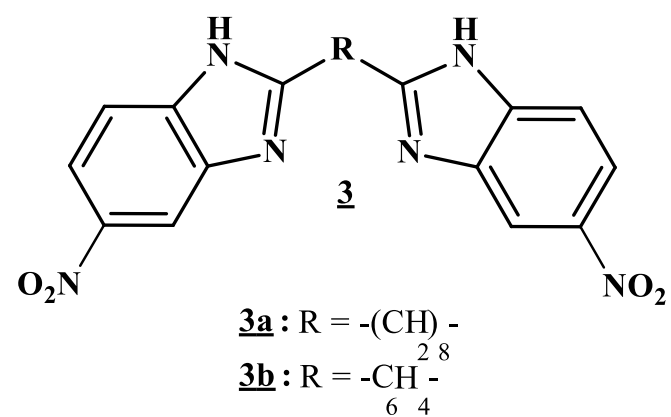

Figure 4. Bis(nitrobenzimidazole)

The reduction was carried out by the use of tin chloride in the presence of acetic acid and hydrochloric acid according to a standard procedure ${ }^{20}$. These compounds are excellent synthetic precursors of other multicyclic heterocycles of imidazobenzodiazepine and imidazoquinolinone types.

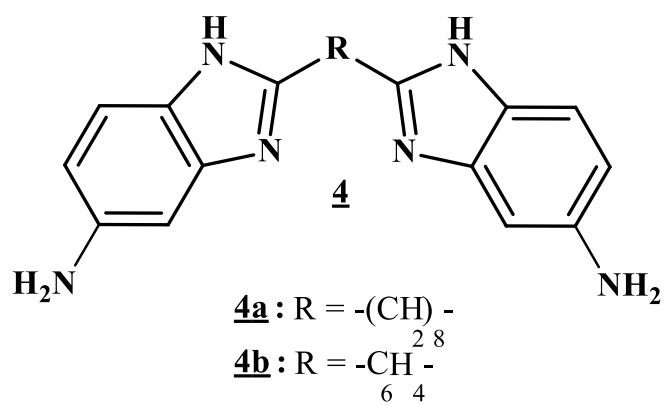

Figure 5. Bis(aminobenzimidazole)

In order to affect the binding of 8-hydroxyquinoline to our Bis-benzimidazole derivatives, we have chosen the "azo" bond as a fixing means such that the preparation requires two synthesis steps: diazotisation and coupling, to discover molecules 2,2'-alkyl/aryl-bis (8-quinolinol-5-azobenzimidazole).

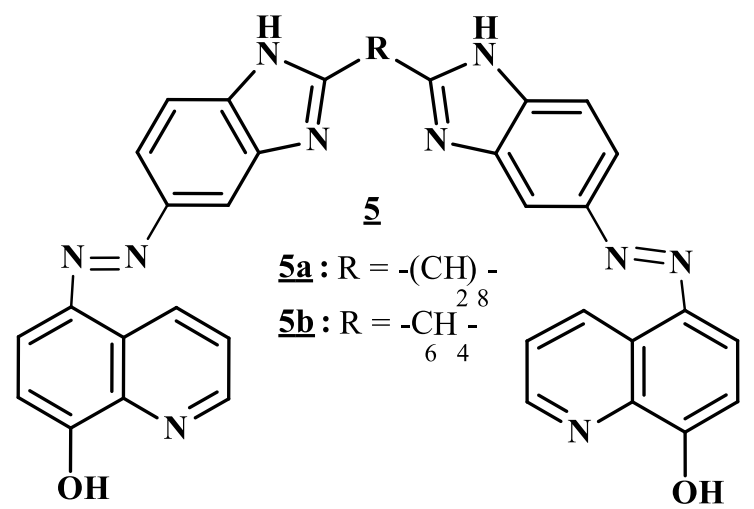

Figure 6. Bis(8-quinolinol-5-azobenzimidazole)

\section{Antioxidant activity}

The measurement of the antiradical activity was tested according to the method developed by Blois ${ }^{21}$ as described by Brand-Williams et al. ${ }^{22}$ with some modifications. The principle of this method is based on the measurement of the free radical scavenging of DPPH (diphenyl picrylhydrazyl) dissolved in methanol $(\mathrm{MeOH})$.

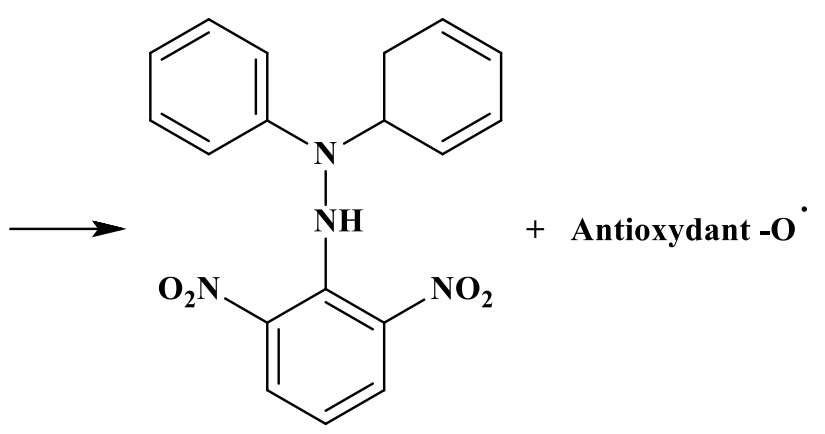

Figure 7. The reaction of an antioxidant with the radical DPPH 
The antioxidant activity of our samples and the standard antioxidant (ascorbic acid) vis-à-vis the DPPH radical was evaluated using a UV spectrophotometer following the reduction of this radical (Fig. 7) which was accompanied by its change from violet (DPPH•) to yellow (DPPH-H) measurable at $517 \mathrm{~nm}$. This reduction capacity is determined by a decrease in the absorbance induced by antiradical substances $^{23}$.

The DPPH solution is obtained by dissolving $4 \mathrm{mg}$ of the powder in $100 \mathrm{ml}$ of methanol. Bisbenzimidazole samples were prepared by dissolving in DMSO at final concentration of $0.2 \mathrm{mg} / \mathrm{mL}$. The test is carried out by mixing $4 \mathrm{~mL}$ of the previous solution of DPPH with $1 \mathrm{~mL}$ of the sample to be tested at different concentrations.

We used ascorbic acid as a reference since it is a known as an efficient scavenger for superoxide $\left(\mathrm{O}_{2}^{-}\right)$, ions, hydrogen peroxide $\left(\mathrm{H}_{2} \mathrm{O}_{2}\right)$, hydroxyl radicals $(\mathrm{HO} \bullet)$, and oxygen singlet $\left({ }^{1} \mathrm{O}_{2}\right)$.

At the end of the incubation period, the absorbance at $517 \mathrm{~nm}$ is read and the antioxidant activity is calculated according to the following formula:

$$
A A \%=100 * \frac{A_{\text {Control }}-A_{\text {test }}}{A_{\text {Control }}}
$$

$\mathrm{A}_{\text {Control: }}$ is the absorbance of the control (containing the different concentrations of the reagent)

$\mathrm{A}_{\text {test: }}$ : is the absorbance of the samples.

AA: is the antioxidant activity

\section{Result and discussion}

After 30 minutes of incubation of the DPPHsample, the solution changes from purple color to yellow in most samples, this change in color is due to the reduction of DPPH, which shows that the samples have a scavenger effect of radical DPPH. The results of the antiradical power by the DPPH of the different samples are gathered in Table 1.

Table 1. DPPH antiradical power assessment.

\begin{tabular}{|c|c|c|}
\hline Samples & Concentration & $\begin{array}{c}\text { Inhibition } \\
\text { rate }\end{array}$ \\
\hline \multicolumn{3}{|c|}{ Bis-benzimidazole } \\
\hline $\begin{array}{l}2 \mathrm{a} \\
2 \mathrm{~b}\end{array}$ & $0,2 \mathrm{mg} / \mathrm{mL}$ & $\begin{array}{l}21,51 \% \\
5,66 \%\end{array}$ \\
\hline \multicolumn{3}{|c|}{ Bis(nitrobenzimidazole) } \\
\hline $\begin{array}{l}3 a \\
3 b\end{array}$ & $0,2 \mathrm{mg} / \mathrm{mL}$ & $\begin{array}{l}28,30 \% \\
38,68 \%\end{array}$ \\
\hline \multicolumn{3}{|c|}{ Bis(aminobenzimidazole) } \\
\hline $4 a$ & $0,2 \mathrm{mg} / \mathrm{mL}$ & $8,91 \%$ \\
\hline
\end{tabular}

$4 b$

$45,38 \%$

Quinoline-Bis-benzimidazoles-Quinoline

\begin{tabular}{ccc}
\hline $5 \mathrm{a}$ & $0,2 \mathrm{mg} / \mathrm{mL}$ & $47,73 \%$ \\
$5 \mathrm{~b}$ & & $43,19 \%$ \\
\hline & References \\
\hline Ascorbic Acid & $0,2 \mathrm{mg} / \mathrm{mL}$ & $60,57 \%$ \\
Hydroxyquinoline & & $42,69 \%$ \\
\hline
\end{tabular}

We note from the previous results that the antioxidant activity of the compounds coupled with the 8-Hydroxyquinoline molecule is significantly greater compared to the unsubstituted Bisbenzimidazole, bis(nitrobenzimidazole) and bis(aminobenzimidazole) but the antioxidant activity of the ascorbic acid of $60,57 \%$ remains high as that of Bis-benzimidazole products. It has been clearly demonstrated that the parent molecules have no significant antioxidant activity while its derivatives have an important antioxidant activity.

Table 2. The percentage inhibition of different concentrations of our samples.

Percentages

\section{Samples Concentration $(\mathrm{mg} / \mathrm{mL}) \quad$ of}

inhibition

\begin{tabular}{|c|c|c|}
\hline \multirow{6}{*}{$4 b$} & 0 & $0,00 \%$ \\
\hline & 0,05 & $33,45 \%$ \\
\hline & 0,1 & $39,66 \%$ \\
\hline & 0,2 & $45,38 \%$ \\
\hline & 0,3 & $46,22 \%$ \\
\hline & 0,4 & $46,39 \%$ \\
\hline \multirow{6}{*}{$5 \mathbf{a}$} & 0 & $0,00 \%$ \\
\hline & 0,05 & $22,35 \%$ \\
\hline & 0,1 & $32,77 \%$ \\
\hline & 0,2 & $47,56 \%$ \\
\hline & 0,3 & $49,58 \%$ \\
\hline & 0,4 & $49,92 \%$ \\
\hline \multirow{6}{*}{$5 b$} & 0 & $0,00 \%$ \\
\hline & 0,05 & $14,29 \%$ \\
\hline & 0,1 & $32,77 \%$ \\
\hline & 0,2 & $43,36 \%$ \\
\hline & 0,3 & $46,55 \%$ \\
\hline & 0,4 & $48,07 \%$ \\
\hline
\end{tabular}


After this step, the compounds which have an DPPH inhibition rate of more than $40 \%$ (highlighted in yellow in Table 1 , compounds $\underline{\mathbf{4 b}}, \underline{\mathbf{5} \mathbf{a}}$ and $\underline{\mathbf{5 b}}$ ), were selected to study their antioxidant activity versus concentration $(0 ; 0,05 ; 0,1 ; 0,2 ; 0,3$ and $0,4 \mathrm{mg} / \mathrm{mL})$. The data obtained is summarized in Table 2 and Fig. 8.

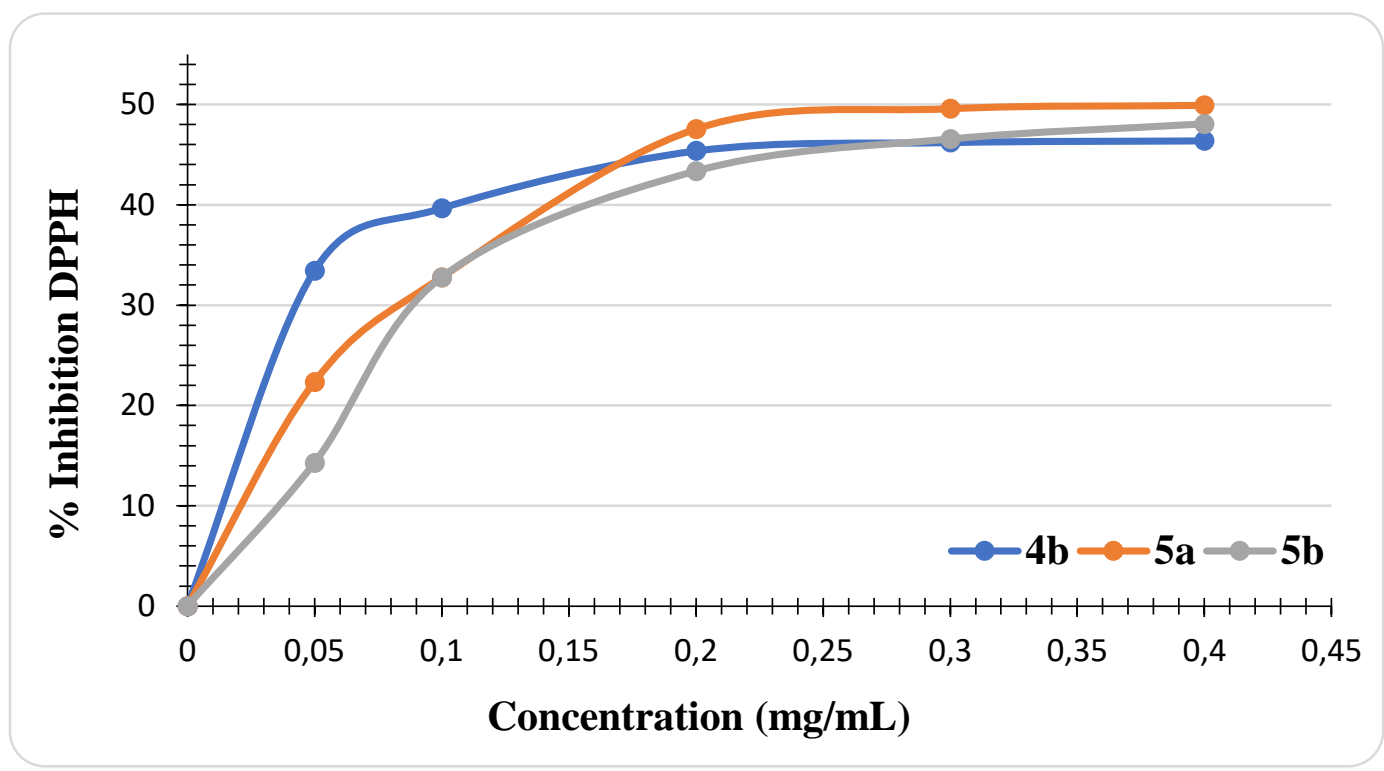

Figure 8. Percentage inhibition curve as a function of the concentration

The inhibition percentages are 46,39\%, 49,92\% and $48,05 \%$ for $\underline{\mathbf{5 b}}$. It is noted that the antioxidant efficiency increases with the concentration.

\section{Conclusion}

This article aims to evaluate and compare the antioxidant efficacy of benzimidazole molecules. The results of the DPPH test revealed that our molecules have very good anti-radical activities.

This study contributes to the knowledge of the antioxidant potentials of our molecules in vitro, it would also be interesting to carry out other studies to evaluate the antioxidant potential in vivo to correlate the results observed in both cases, and publish them soon.

\section{Acknowledgments}

This work financially supported by an Excellence Grant accorded to Amine OUAKET (42UH2C2017) by the National Center of Scientific and Technical Research (CNRST) - Ministry of Higher Education, Scientific Research and Training, Morocco.

\section{Conflict of interest}

The authors declare that they have no conflict of interest.

\section{References}

1 - A. Ouaket, S. Hamdouch, F. Moughaoui, Z. Anbaoui, M. Berrada, A. Bennamara,
N. Knouzi, Synthesis and Characterization of 2, 2'-Alkyl/Aryl- Bis(Quinoline-8-Ol-5-

Azobenzimidazole), IJPPR.Human, 2018, 11(2), 231-238.

2 - A. G. Montalban, Quinolines and Isoquinolines: Heterocycles in Natural Product Synthesis; ed. By K. C. Majumdar, S. K. Chattopadhyay; Wiley-VCH: New York, 2011, pp. 299- 339.

3 - (a) D. Lednicer, Membered heterocycles: The Organic Chemistry of Drug Synthesis; ed. John Wiley \& Sons: Hoboken, New Jersey, 2007, Vol.7, pp. 84-216.

(b) V. Lee, S. J. Hecker, Antibiotic resistance versus small molecules, the chemical evolution, J. Med. Res. Rev., 1999, 19, 521-542

4 - I. B. Onyeachua, I. B. Obot, A. A. Sorour, M. I. Abdul-Rashid, Green corrosion inhibitor for oilfield application I: Electrochemical assessment of 2-(2-pyridyl) benzimidazole for API X60 Steel under sweet environment in NACE brine ID196, Corrosion Science, 2019, 150, 183-193.

5 - R. Walia, M. Hedaitullah, S. Farha Naaz, K. Iqbal, H. S. Lamba, Benzimidazole derivatives - An overview, IJRPC, 2011, 1(3), 565-574.

6 - S. Gurvinder, K. Maninderjit, C. Mohan, Benzimidazoles: The latest information on biological activities, IRJP, 2013, 4(1), 82-87.

7 - N. Srestha, J. Banerjee, S. Srivastava, A review on chemistry and biological significance of benzimidazole nucleus, IOSR Journal of Pharmacy, 2014, 4(12), 28-41. 
8 - J. B. Wright, The Chemistry of the Benzimidazoles, Chem. Rev., 1951, 48(3), 397-541.

9 - U. Kalidhar, A. Kaur, An overview on Some Benzimidazole and Sulfonamide derivatives with antimicrobial activity, RJPBCS, 2011, 2(4), 1116-1135.

10 - E.M. Essassi, L'utilisation des 1,5benzodiazepines en synthese heterocyclique, Bull. SOC. Chim. Belg., 1994, 103(11), 680-686.

11 - Y. Okamoto, K. Takagi, Chemistry of 4-amino1H-1,5-benzodiazepine-3-carbonitrile, J. Heterocyclic Chem., 1987, 24, 885-891.

12 - K. Attar, H. Camara, M. Benchidmi, E. M. Essassi, B. Garrigues, Synthèse de nouveaux dérivés du 1-hydroxyindole et du pyrazole. Comptes Rendus Chimie, 2002, 5(6-7), 551-557.

13 - D. S. Vanvliet, P. Gillespie, J. J. Scicinski, Rapid one-pot preparation of 2-substituted benzimidazoles from 2-nitroanilines using microwave conditions, Tetrahedron Lett., 2011, 46(39), 6741-6743.

14 - S. J. Teague, S. Barber, S. King, L. Stein, Synthesis of benzimidazole-based JNK inhibitors, Tetrahedron Lett., 2005, 46(27), 4613-4616.

15 - A. Bali, Y. Bansal, M. Sugumaran, J. S. Saggu, P. Balakumar, G. Kaur, G. Bansal, A. Sharma, M. Singh, Design, synthesis, and evaluation of novelly substituted benzimidazole compounds as angiotensin II receptor antagonists, Bioorg. Med. Chem. Lett., 2005, 15(17), 3962-3965.

16 - R. T. Stibrany, M. V. Lobanov, H. J. Schugar, J. A. Potenza, A Geometrically Constraining Bis(benzimidazole) Ligand and Its Nearly
Tetrahedral Complexes with Fe(II) and Mn(II), Inorg. Chem., 2004, 43(4), 1472-1480.

17 - M. J. S. Moreno, A. F. Bottello, R. B. GomezCoca, R. Griesser, J. Ochocki, A. Kotynski, J. N. Gutierrez, V. Moreno, H. Sigel, Metal IonBinding Properties of (1H-Benzimidazol-2-ylmethyl)phosphonate (Bimp2-) in Aqueous Solution. Isomeric Equilibria, Extent of Chelation, and a New Quantification Method for the Chelate Effect, Inorg. Chem., 2004, 43(4), 1311-1322.

18 - F. Arjmand, B. Mohani, S. Ahmad, Synthesis, antibacterial, antifungal activity and interaction of CT-DNA with a new benzimidazole derived $\mathrm{Cu}(\mathrm{II})$ complex, Eur. J Med. Chem., 2005, 40(11), 1103-1110.

19 - Y. Chew, Y. Lim, Evaluation and Comparison of Antioxidant Activity of Leaves, Pericarps and Pulps of Three Garcinia Species in Malaysia, Free Radicals and Antioxidants, 2018, 8(2), 130-134.

20 - G. Persaud, F. F. Cantwell, Determination of free magnesium ion concentration in aqueous solution using 8-hydroxyquinoline immobilized on a nonpolar adsorbent, Anal. Chem., 1992, 64(1), 89-94.

21 - M.S. Blois, Antioxidant Determinations by the Use of a Stable Free Radical, Nature, 1958, 181, 1199-1200.

22 - W. Brand-Williams, M.E.Cuvelier, C.Berset, Use of a free radical method to evaluate antioxidant activity, LWT - Food Science and Technology, 1995, 28(1), 25-30.

23 - L. Majhenič, M. Škerget, Ž. Knez, Antioxidant and antimicrobial activity of guarana seed extracts, Food Chemistry, 2007, 104(3) 1258-1268. 